\title{
N-LiNe WEAR DETECTION OF MILLING TOOLS USING A DISPLACEMENT FIBER OPTIC SENSOR
}

\section{E. Castillo-Castañeda}

Universidad Autónoma de Querétaro, Facultad de Ingeniería, Centro Universitario, 76010 Querétaro, México

Tel: (442) 2163959 ext. 227, Fax: (442) 2163599 ext. 103

E-mail: ecast@sunserver.uaq.mx

Received: August 23 2001 and accepted March $5^{\text {th }} 2002$

\begin{abstract}
A cost-effective technique for on-line wear monitoring of a milling tool is presented. The tool wear is estimated directly from a fiber optic sensor with high resolution and high bandwidth characteristics. This sensor provides a distance measurement between its probe and the tool profile. The contribution of this work is the application of this sensor to sense on-line wear of a milling tool. Since the light emitted by this sensor comes from a photodiode, it does not produce eye damage, this is safer than laser displacement sensors. This technique senses the tool wear in real time, while the tool is rotating, with an accuracy less than 1 micron. Experimental results are also presented for a four-flank cutting tool rotating at $300 \mathrm{rpm}$.
\end{abstract}

RESUMEN

Se presenta una técnica de alto costo-beneficio para el monitoreo en línea del desgaste de una herramienta de fresado. El desgaste es estimado directamente a partir de un sensor de fibra óptica con características de alta resolución y alto ancho de banda. Uno de esos grupos transmite luz y el otro grupo recibe la luz reflejada desde una superficie objetivo. La contribución de este trabajo es la aplicación de este sensor para monitorear en línea el desgaste de una herramienta de fresado. Ya que la luz emitida por este sensor proviene de un fotodiodo, esta no produce daño a los ojos, esto la hace más segura que los sensores de desplazamiento láser. Esta técnica permite monitorear el desgaste de la herramienta en tiempo real mientras la herramienta gira, con una precisión inferior a 1 micra. También se presentan resultados experimentales para una herramienta de corte con cuatro filos que gira a $300 \mathrm{rpm}$.

KEYWORDS: Optical inspection, Wear detection, Tool condition monitoring, Fiber optic sensors.

\section{INTRODUCTION}

During the machining processes such as turning or milling, where hard material is removed, the wear of the cutting tool reduces considerably the quality of the workpiece. In spite of actual technology to estimate the wear of the cutting tool, the manufacturing industry still uses mainly empirical methods to evaluate the tool life, for example the number of machining hours. Figure 1 shows a machining process using a rotating fourflank cutting tool, which is the type of tool profile considered in this work. The feed motion is generated by the worktable driven by linear stages; the rotation of the tool is produced by the main spindle, usually an AC motor controlled in velocity. The speed rotation and the feed rate depend on the workpiece material and the depth of cut. One can observe that for a given instant only one flank is in contact with the material. If one contact flank is worn the next cutting flank should remove also the surplus material from the previous

Vol. 1 No. 2 July 2003 
one, then at this moment the cutting force increases. Because of this fact, the first technique to detect the tool wear was done using a force sensor.

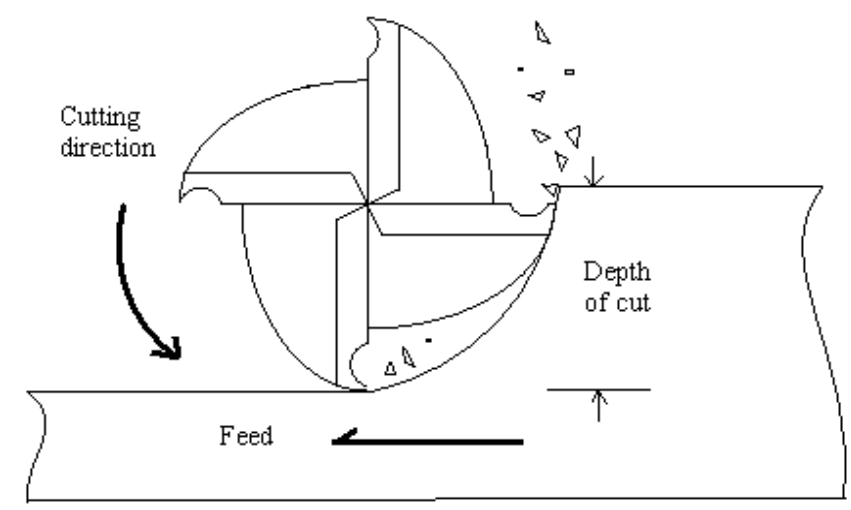

Figure 1. Tool motion during cutting

Since many years, in most of manufacturing industries, tool life has been estimated as a number of machining hours. When this empirical number expires, the tool has to be removed whether or not it is still in good conditions. Evidently, this empirical method is only suitable when the tool is used in exactly the same cutting conditions during all its life and the work piece material is sufficiently homogeneous to ensure a similar wear for a similar machining time. In very few cases, tool wear is verified by off-line methods, by human visual inspection, to decide if it is still in good conditions for machining. In any case, the best way to ensure the quality of a final machining is to guarantee that the tool wear remains within a predefined range, if this range is surpassed the tool must be immediately changed by a new one. Figure 2 shows the milling tool geometry considered for this work.
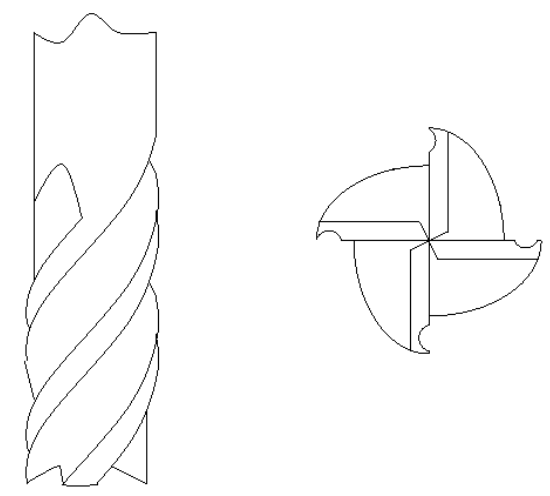

Figure 2. Milling tool geometry

Some techniques have been already developed for on-line monitoring for detecting tool wear or tool breakage. The most common method is the spindle current monitoring. As it was stated before, when one flank of the cutting tool is worn, the next flank should remove the surplus material, then the cutting force increases, producing an increment of the spindle current. When the spindle current exceeds a predefined set point, the machining process is automatically stopped, sending a message to the operator to check the whole system or to replace the tool. This method is mainly used for tool breakage because in such case the spindle current variation becomes more evident. A second method that has been already used with success by several industries is to monitor the acoustic emission signal produced during the cutting process [1]. In a similar way that the previous method, when the signal reaches predefined limits, the cutting process is stopped. The work performed at Technical University of Warsaw presented in [2] shows 
a technique to detect the tool failure by using a statistical analysis of the acoustic emission signal. At the Technical University of Chemnitz, Germany, the acoustic emission signal method has been also used to estimate the quality of the machined surface during turning processes [3], that is an alternative method to estimate also the roughness of the workpiece. At the Mechanical Engineering Laboratory in Tsukuba, Japan, an application of the Wavelet transform was developed for on-line detection of tool breakage during machining process [4]. In that case, the monitored signal was the cutting force sensed at the worktable level. The work reported in [5], performed at the University of Paderborn, Germany, presents a multisensor system based on neural nets for monitoring several correlated variables of a turning process to evaluate the tool condition.

The common strategy of all the previous works has been the implementation of indirect methods to estimate the tool condition based on the monitoring of physical signals that are correlated with the tool wear or breakage, such as the spindle current, acoustic emission, and cutting force. Thus, the main problem is to find a correlation function between one of those signals and tool wear or breakage. The reliability of the relationship between indirect measurements and the tool condition is a serious problem to be overcome when several cross-correlated variables influence the condition of the tool. As a result of this, the work in [6] proposes a monitoring method based on both cutting forces monitoring and flank wear measurements using a vision system [7-9]. Based on experimental analysis, a flank wear curve is estimated by giving a prediction of the tool-life. A review of indirect methods for tool wear monitoring is presented in [10].

Following the idea of an in-process direct monitoring, Dr. Ryabov from Mechanical Engineering Laboratory in Tsukuba, Japan, presents in [11] a method for detecting tool failures by using a laser sensor. However, as it's well known light reflected from laser sensors can produce eye damage.

The work presented in this paper proposes a direct method for on-line tool condition monitoring while the tool is rotating. It is being carried out at the Universidad Autónoma de Querétaro, Mexico. The main contribution is to propose an innovative direct method, based on a displacement fiber optic sensor (photonic sensor) for monitoring the tool wear in real time with an accuracy less than one micron.

\section{THE DISPLACEMENT FOTONIC SENSOR}

\subsection{The fiber sensor}

The recent growth of activity in fiber optic sensors has lead to a great variety of technically sophisticated devices employing interference, polarization, and wavelength modulation techniques [12]. In spite of all, these methods offer great promise to certain specific applications and dedicated sensors, the intensity modulated Fiber Optic Displacement Sensor offers a powerful combination of simplicity, performance, versatility, and low cost, which make it well suited for a wide variety of laboratory and industrial applications. Moreover, since the light emitted by this type of sensor comes from a photodiode it does not produce eye damage, then it is safer than laser displacement sensors.

\subsection{Parameter analysis}

The basic principle employed in the Fiber Optic Lever Displacement Transducer [13] is to use two sets of fiber optic elements, one to carry light from a remote source to an object or target whose displacement or motion is to be measured, and the other to receive the light reflected from the object and carry it back to a photo sensitive detector. A very common fiber optic probe is a bifurcated bundle fiber [14], as shown in Figure 3. 


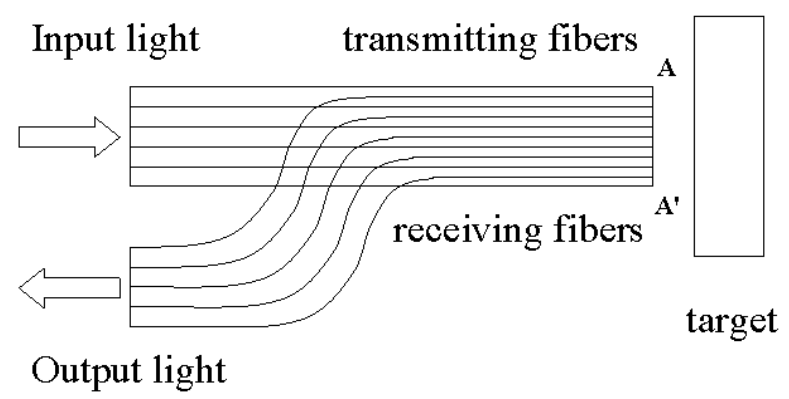

Figure 3. Bifurcated bundle fiber

The light emitted from one bundle is back-reflected by the target and collected by another bundle (receiving fibers). As a result, the returned light at the detector is distance-modulated. The mathematical analysis of a photonic sensor is considerably simplified by the assumption that uni-angular electro luminescent energy is coupled into loss-less, non-dispersing, and otherwise ideal step-index fibers with negligible cladding thickness. Further simplification results when the sensor consists of a single centered transmitting fiber surrounded by six symmetrical receiving fibers (radius equal to $r_{0}$ ) as shown in Figure 4 . This figure shows the exit and reflected patterns at the exit/return plane. The area of receiving fibers illuminated by reflected light (reflected ring radius $x$ ) is proportional to the target distance $y$ (standoff distance). The distance $d x$ represents $x$ variations when distance from probe to target varies $(d y)$. The characteristic parameters associated to this sensor can be determined from the knowledge of: the angle $\phi$ and the emittance level of the exit illumination, the geometric relationships between transmitting and receiving fibers, and the distance from fiber-tip to target.

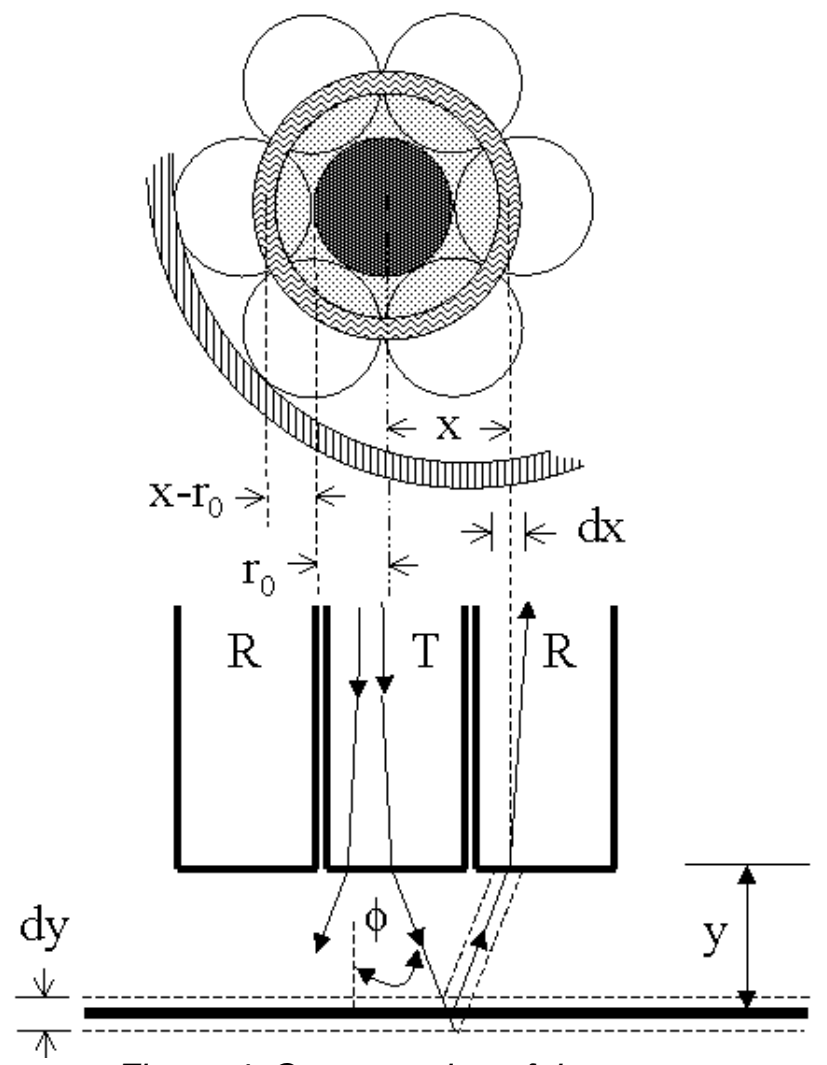

Figure 4. Cross section of the sensor 
The mathematical relationships of the displacement sensor, such as: the geometric sensitivity, the displacement sensitivity, the optical detection limit, and the displacement detection limit, will be derived in the next section. In this work, the sensitivity was defined as the rate of change of the standoff distance due to a change in a parameter.

The geometric sensitivity $\left(\alpha_{G}\right)$ is defined as the relationship between the standoff distance variations and the distance-modulated area of reflected light on the fiber termination plane, i.e., $\alpha_{G}=\frac{d y}{d A}$

From trigonometry, it is a function of the fiber radius and illumination exit angle only. When fiber cladding is negligible, the standoff distance is given by

$$
y=\frac{x-r_{0}}{2 \tan \phi}
$$

By defining a parameter $q=x / r_{0}$, the equation (1) can be rewritten as

$$
y=\frac{(q-1) r_{0}}{2 \tan \phi}
$$

The distance-modulated area of the reflected ring on the fiber termination plane is given by $d A=2 \pi x d x$. The first derivative of equation (2) respect to this area is given by:

$$
\frac{d y}{d A}=\frac{1}{2 \tan \phi} \frac{d x}{d A}
$$

Then the $\alpha_{G}$ referred to this plane is

$$
\frac{d y}{d A}=\frac{1}{4 \pi x \tan \phi}
$$

The displacement sensitivity $\left(\alpha_{D}\right)$ of a fiber optic sensor is determined by the manner in which the optical radiometric power $\left(p_{O R}\right)$ reaching the photo-detector varies with the target distance, i.e., $\alpha_{D}=\frac{d y}{d p_{O R}}$

The nonlinear contributions of the $\alpha_{D}$ are incorporated into a term $\widetilde{s}=d q / d \widetilde{p}_{O R}$, where $\widetilde{p}_{O R}=\frac{p_{O R}}{p_{\max }} \cdot p_{\max }$ is the maximum subtended power. The differentiation of this term and equation (4) lead to:

$$
\alpha_{D}=\frac{\widetilde{s} r_{0}}{2 p_{\max } \tan \phi}
$$

The subtended power of the receiving fibers is the product of the receiving fiber subtended area and the irradiance. Figure 5 shows the interaction of three adjacent transmitting and receiving fibers as the light is reflected from a target a the single angle $\phi$. It can be seen that a zero gap, the light in the transmitting fiber would be reflected directly back into itself and little or no light would be transferred to the receiving fiber. As the gap increases, some of the reflected light is captured by the receiving fiber and carried to the photo sensitive detector. As the gap increases, a distance will be reached at which a maximum of reflected light is transferred to the receiving fiber. Further increases in the gap will result in a decrease in the light at the receiving fiber face and a corresponding drop in the output signal from the photo sensor. The gap and displacement range over which the initial rise in signal takes place and at which the maximum occurs is primarily determined by the diameter and the numerical aperture of the fibers and the intensity distribution within the operating field of the fibers. In order to obtain the higher levels of intensity at the photo detectors, 
commercial devices of this type uses multiple transmitting and receiving fibers. The irradiance of the targetreflected illumination on the entrance plane of the receiving fibers may be derived from the geometry shown in Figure 5. Indeed, since all rays are meridional and uniformly distributed within the illuminated fiber, they exit at the single angle $\phi$. Figure 5 shows that two different irradiances appear on a target located on plane B, a uniformly bright spot surrounded by a uniformly annular ring portion. When the target distance reaches the $\mathrm{C}$ plane the bright spot disappears and an annular ring appears (from $\mathrm{C}$ plane to target plane). The width of this annular ring is equal to the fiber diameter.

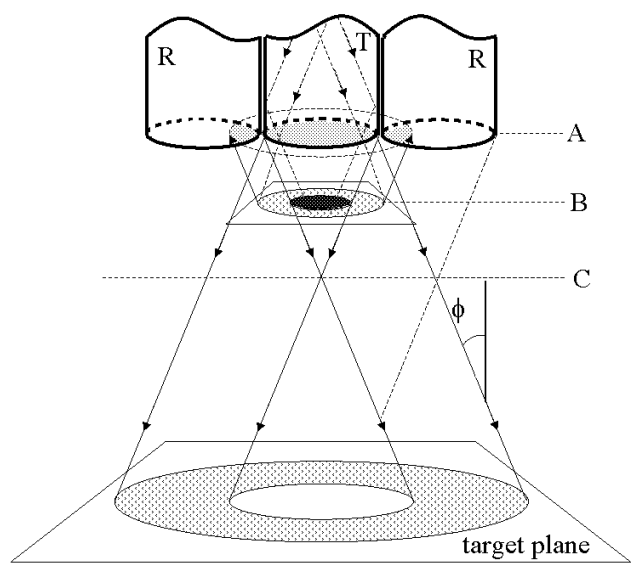

Figure 5. Interaction between transmitting and receiving fibers

These two irradiances appear from zero to plane C. Figure 6 shows more clearly that patterns of reflected light on $\mathrm{B}$ and $\mathrm{C}$ planes are annular rings, diverging cone, and not uniformly illuminated disks since the rays exit the illuminating fiber are not perpendicular to those planes.

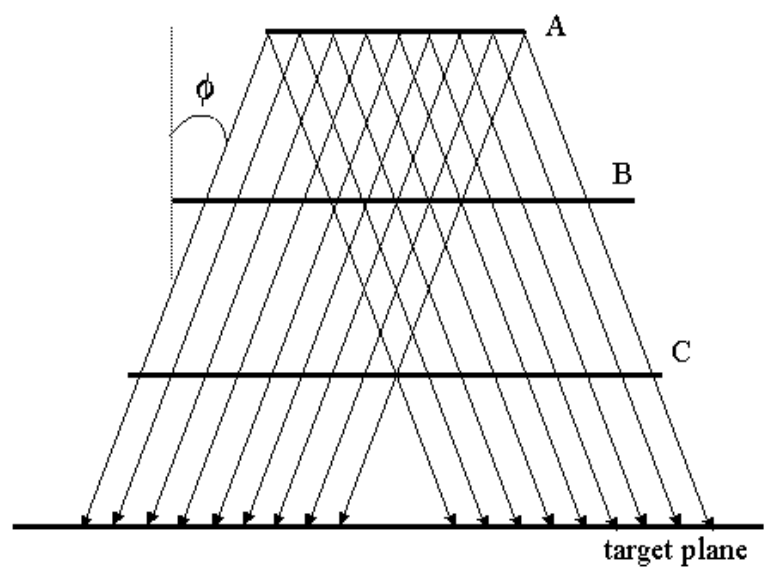

Figure 6. Reflected patterns

The $\mathrm{C}$ plane distance is given by

$$
\overline{A C}=\frac{r_{0}}{\tan \phi}
$$


The optical detection limit $\left(\beta_{O D}\right)$ is determined by the modulations in radiometric power. It can be determined from the shot-noise relationship [15]

$$
I_{S H}=\left(p_{O R} \gamma 2 e B W\right)^{1 / 2}
$$

then the $\beta_{O D}$ is given by

$$
\beta_{O D}=\frac{I_{S H}}{\gamma}
$$

where $I_{S H}$ is the RMS noise current, $\gamma$ is the responsitivity of the photo-detector, $e$ is the electron charge, and $B W$ is the noise current bandwidth.

The displacement detection limit $\left(\beta_{D D}\right)$ of fiber sensors is the product of the $\alpha_{D}$ in displacement per watt and the optical detection limit $\left(\beta_{O D}\right)$ in watts, i.e.,

$$
\begin{aligned}
& \beta_{D D}=\alpha_{D} \beta_{O D} \\
& =\widetilde{s}\left[\frac{r_{0}}{2 p_{\max } \tan \phi}\right] \frac{\left(p_{O R} \gamma 2 e B W\right)^{1 / 2}}{\gamma}
\end{aligned}
$$

Defining $\tilde{d}=\tilde{s}\left(\tilde{p}_{O R}\right)^{1 / 2}$, equation (9) becomes

$$
\beta_{D D}=\widetilde{d} \frac{p_{\max }^{1 / 2}}{1 / 2} p_{O R}^{1 / 2}\left[\frac{r_{0}}{2 p_{\max } \tan \phi}\right] \frac{\left(p_{O R} \gamma 2 e B W\right)^{1 / 2}}{\gamma}
$$

that can be reduced to

$$
\beta_{D D}=\tilde{d} \frac{r_{0}}{\tan \phi}\left(\frac{e B W}{2 p_{\max } \gamma}\right)^{1 / 2}
$$

Since nothing in the fiber optic sensors limits the bandwidth, this is determined only by the electronic circuitry. Some of the numerical values of the previous parameters are presented in the next section and were verified experimentally. The work presented in [16] gives additional information on the theoretical and experimental verification of the parameters of multiple fiber transducers.

\subsection{The Sensor Probe}

The photonic sensor that has been used in this work, shown in Figure 7, is a fiber-optic device model KD300 from MTI Instruments, provided with a sensor probe MTI-2125-R.

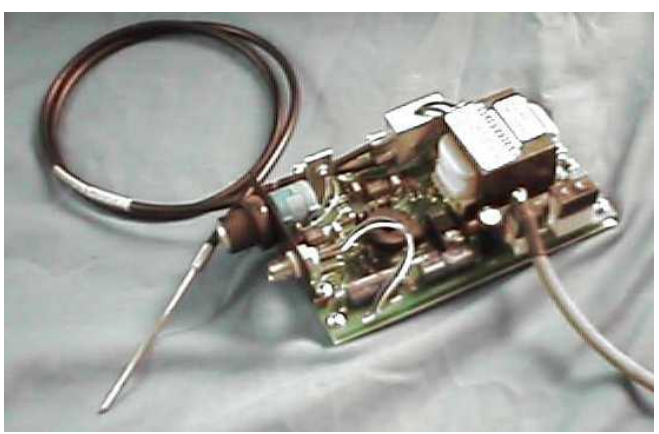

Figure 7. The Displacement Photonic Sensor 
The main characteristics of this sensor are as follows:

Probe tip diameter: $2.28 \mathrm{~mm}$,

Maximum frequency response: $150 \mathrm{KHz}$,

Displacement detection limit: $0.25 \mu \mathrm{m}$,

Displacement sensitivity: $0.76 \mu \mathrm{m} / \mathrm{mV}$,

Linear range: $3.05 \mathrm{~mm}$,

Standoff distance: $6.09 \mathrm{~mm}$,

Optical peak: $1.22 \mathrm{~mm}$.

This fiber-optic probe has two groups of optical fibers bundled together in a random configuration, as shown in Figure 8a. The sensor converts the amount of reflected light into an electrical signal that is proportional to the distance from the probe to the target surface. The response curve that correlates the voltage output of the sensor and the gap to the target surface is shown in Figure $8 \mathrm{~b}$. The initial rising portion of the curve, the front slope, is very sensitive and is the operating range used for high accuracy measurements. The declining section of the curve, the back slope, is used for measurements that require greater standoff distances.

Receiving fiber

Transmitting fiber

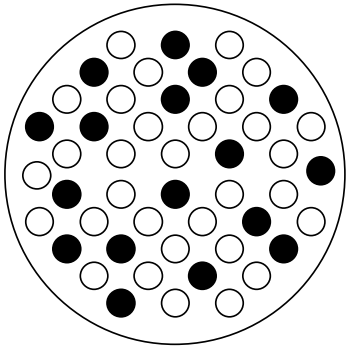

a)

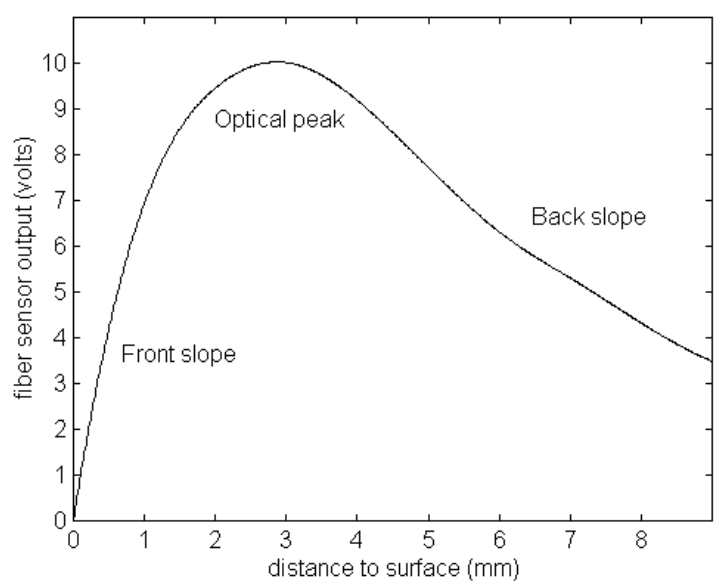

b)

Figure 8. a) Fiber distribution, b) Response curve

In the analysis of sensitivity of the sensor presented in this work, the reflected light was assumed specular reflection in order to simplify the drawings, however the reflection light on the surface of the milling tool is evidently diffuse reflection.

\section{THE EXPERIMENTAL SETUP}

The experimental setup for this work is composed by a SHIZUOKA 3-axis milling machine, a data acquisition board with sample period of $150 \mathrm{KHz}$, the displacement photonic sensor, and a PC with a Pentium processor at $400 \mathrm{MHz}$. 


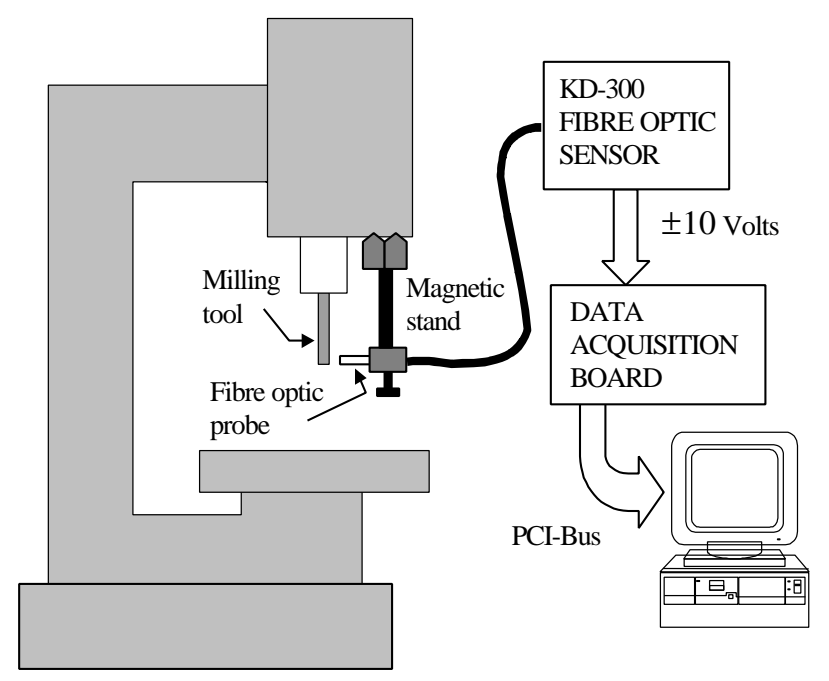

Figure 9. The experimental setup

The sensor was mounted in a magnetic base and was located in front of the rotating tool, as shown in Figure 10, with a gap of $2 \mathrm{~mm}$ to sense the tool profile during motion. The sensor is working on the front slope to increase the sensitivity of the measurement. The speed rotation of the main spindle was 300 RPM.

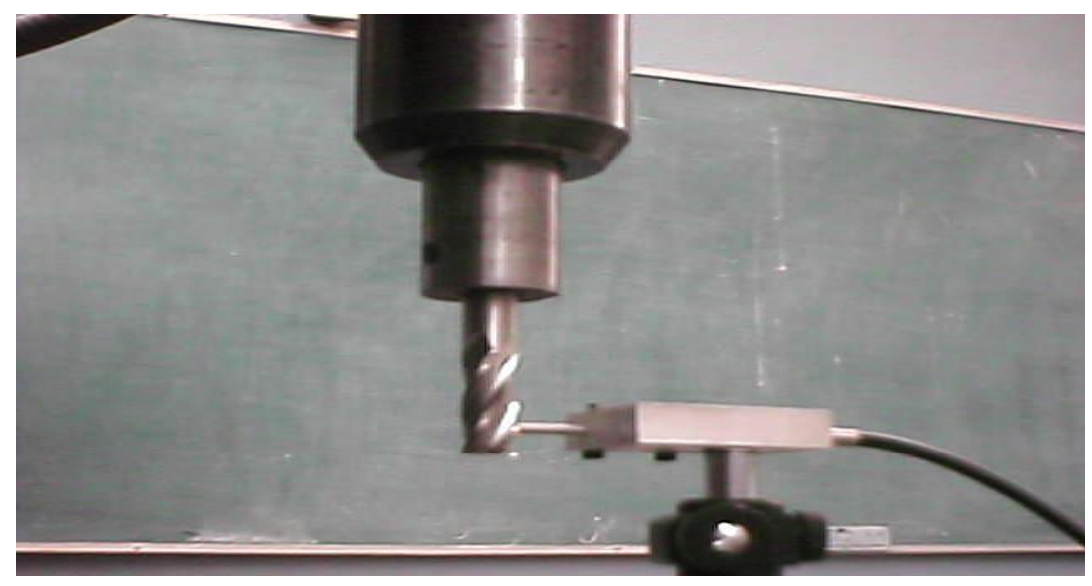

Figure 10. Sensor and milling tool

\section{RESULTS}

Figure 11 shows the sensor response when one of the four flanks of the tool is worn. One can clearly identify the different flanks for each revolution of the tool. The circled area shows that the signal corresponding to the third flank varies respect to the other flanks due to wearing. Figure 12a shows the corresponding polar plot of the output sensor using a new cutting tool. Since the sensor is located in front of the tool when it is rotating, the tool profile can be "reconstructed" after one tour. As it can be seen, the tool has four teeth with similar shape. Figure $12 b$ shows the polar plot of the output sensor for a worn tool; the wear is located around 300 degrees of the tool profile, i.e., the third and fourth teeth are concerned. 


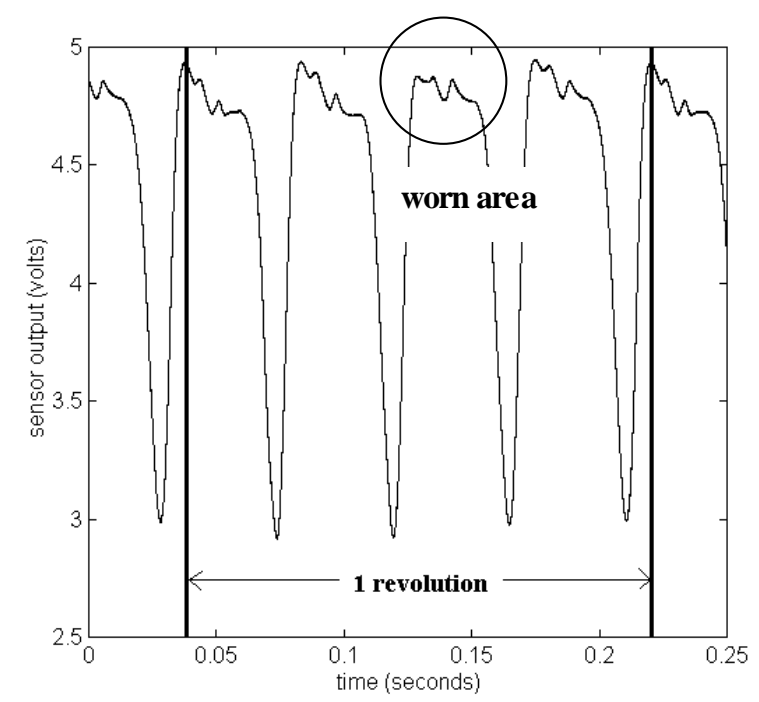

Figure 11. Sensor output plot while a worn tool is rotating

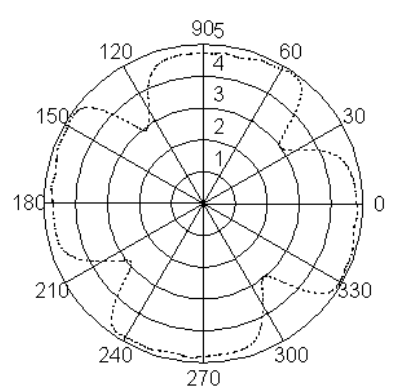

a)

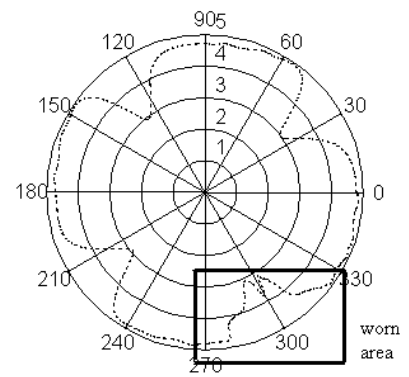

b)

Figure 12. Polar plots for a) new tool, b) worn tool

\section{CONCLUSION AND FUTURE WORKS}

A direct method for on-line wear detection of a rotating tool is presented. Instead of a high cost laser displacement sensor, this simple and low cost fiber optic sensor performs good quality measurements of the tool wear. The direct method developed has the ability to "reconstruct" the tool profile after only one tour of the tool, then it provides a very fast and accurate on-line method. In order to protect the sensor from sharp strips of metal, compressed air can be blown by a nozzle located near the sensor. The sensor response curve varies depending on the type of material of target surface, thus it has to be calibrated for each tool material. This technique can also be used in many other situations of on-line detection failures such as automatic crack detection of metal sheets.

\section{ACKNOWLEDGMENTS}

This study was supported by the Mexican Council for Science and Technology (CONACYT), project number 26265-A. The author would like to express his gratitude to the Universidad Autónoma de Queretaro, Mexico, for giving its support to develop this project. 


\section{REFERENCES}

[1] Atam-4000 Control Station, "Operation Manual, Atam Systems Incorporated", Worthington, Ohio 43085, U.S.A., 1997.

[2] Jemielniak, K. and Otman, O., "Catastrophic Tool Failure Detection Based on Acoustic Emission Signal Analysis", Annals of CIRP, Vol. 47/1, pp 31-34, 1998.

[3] Meyer, W., Neumann, U., and Hörl, H., "Acoustic Emission Measurement for Quality Control and Process Monitoring in Cutting Operations", Report of the Technical University of Chemnitz, Faculty of Mechanical Engineering and Material Processing, Germany, 1996.

[4] Kasashima, N., Mori, K., and Taniguchi, N., "On line Failure Detection in Face Milling Using Discrete Wavelet Transform", Annals of the CIRP, Vol. 44, pp. 483-487, 1995.

[5] Barschdorff, D., Monostori, L., Kottenstede, T., Warnecke, G., and Müller, M., "Cutting Tool Monitoring in Turning under Varying Cutting Conditions: An Artificial Neural Network Approach", Proceedings of the Sixth International Conference on Industrial and Engineering Applications of Artificial Intelligence and Expert Systems, pp. 353-359, Edinburgh, Scotland, 1993.

[6] Novak, A., "On-Line Prediction of the Tool Life", Annals of the CIRP, Vol. 45, pp. 93-96, 1996.

[7] Kurada, S. and Bradley, C., "A review of machine vision sensors for tool condition monitoring", Computers and Industry, 34 (1), 1997, pp.55-72.

[8] Oguamanam, D.C.D., Raafat, H., and Taboun, S.M., "A machine vision system for wear monitoring and breakage detection of single-point cutting tools", Computers in Industrial Engineering, 26 (3), 1994, pp. 245-251.

[9] Wong, Y.S., Nee, A.Y.C., Li X.Q., Reisdorf, C., "Tool condition monitoring using a laser scatter pattern", Journal of Materials Processing Technology, Vol. 63, pp. 205-210, 1997.

[10] Dimla, E. and Dimla, Snr., "Sensor signals for tool-wear monitoring in metal cutting operations-a review of methods", International Journal of Machine Tools \& Manufacture", 40, 2000, pp. 10731098.

[11] Ryabov, O., Mori, K., Kasashima, N., Uehara, K., "An In-process Direct Monitoring Method for Milling Tool Failures Using a Laser Sensor", CIRP Annals, Vol. 45, No.1, 1996.

[12] Johnson, M., "Fiber Displacement Sensors for metrology and Control", Optical Engineering, Vol.24, No. 6, pp. 961-965, Nov./Dec., 1985.

[13] Cook, R.O., and Hamm, C.W., "Fiber Optic Lever Displacement Transducer", Applied Optics, Vol. 18, pp. 3230-3240, Oct. $1,1979$.

[14] Dakin, J., Culshaw, B., "Optical Fiber Sensors: Systems and Applications”, Artech House Inc. 1989.

[15] Larach, S., "Photo electronics Devices and Materials", Chapter 5, Van Nostrand, Princeton, N.J., 1965.

[16] Hoogenboom, L., Allen, G.H., \&Wang, S., "Theoretical and Experimental Analysis of a Fiber Optic Proximity Probe", S.P.I.E. Technical Symposium, East 84, Arlington, Virginia, April 29, 1984, Paper No. 478-25.

\section{Author Byography}

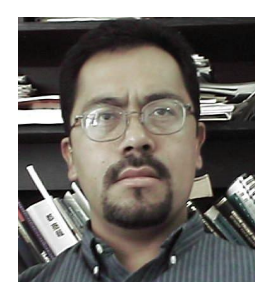

\section{EDUARDO CASTILLO-CASTAÑEDA}

Was born in Mexico City in 1963. He received the Bachelor degree in Ingeniero Electro-Mecánico de la Universidad Nacional Autónoma de México (Electro-mechanical Engineering at the National Autonomous University of Mexico) in 1987 and the Ph. D. in Automatic Control at the National Polytechnic Institute of Grenoble, France, in 1994. He was Invited Researcher at the Mechanical Engineering Laborartory in Tsukuba, Japan, from 1997 to 1998 . He is full time professor at the Faculty of Engineering of the Uiversidad Autónoma de Queretaro (Autonomous University of Queretaro), Mexico. His research interest are Precision Manufacturing Machinery and Mechatronics.

Vol. 1 No. 2 July 2003 